\title{
Archives
}

\section{MOT DE LA RÉDACTION}

\section{VIVIANNE MARÉCHAL}

Volume 46, numéro 2, 2017

URI : https://id.erudit.org/iderudit/1040374ar

DOI : https://doi.org/10.7202/1040374ar

Aller au sommaire du numéro

Éditeur(s)

Association des archivistes du Québec (AAQ)

ISSN

0044-9423 (imprimé)

2369-9256 (numérique)

Découvrir la revue

Citer ce document

Maréchal, V. (2017). MOT DE LA RÉDACTION. Archives, 46(2), 4-4.

https://doi.org/10.7202/1040374ar

Ce document est protégé par la loi sur le droit d'auteur. L'utilisation des services d'Érudit (y compris la reproduction) est assujettie à sa politique d'utilisation que vous pouvez consulter en ligne.

https://apropos.erudit.org/fr/usagers/politique-dutilisation/
Cet article est diffusé et préservé par Érudit.

Érudit est un consortium interuniversitaire sans but lucratif composé de l'Université de Montréal, l'Université Laval et l'Université du Québec à Montréal. Il a pour mission la promotion et la valorisation de la recherche. https://www.erudit.org/fr/ 


\section{MOT DE LA RÉDACTION}

Chers collègues et lecteurs,

Le Comité de la revue Archives (CORA) est heureux de vous faire parvenir ce nouveau numéro, avec un retard malheureusement. Nous avons d'excellentes raisons! Remarquez les changements à la présentation de la revue, le nouveau logo et le nouveau format de lecture pour tablette qui vous est offert (ePub)! Ce travail de refonte de l'identité visuelle de la revue a pris du temps et nous sommes fiers du résultat. Nous espérons que cela vous plaira!

Lorsque nous avons été approchés par Diane Baillargeon, directrice de la Division de la gestion de documents et des archives de l'Université de Montréal (DGDA), pour publier les textes du colloque sur le $50^{\mathrm{e}}$ anniversaire de la DGDA, nous avons sauté sur l'occasion de souligner la contribution de cette importante institution à l'archivistique québécoise, d'autant que la revue a été marquée dès ses débuts par la participation des membres de la DGDA au CORA et pensons au dévouement de Michel Champagne ces dernières années. Ces membres ont également fait partie de la grande famille des auteurs ayant publié dans la revue, remportant même de nombreux prix pour le meilleur article.

Ce numéro a donc un ton plus personnel que ce que nous avons I'habitude de publier. Pour ne pas dénaturer les textes en leur enlevant cette importante dimension émotive, ceux-ci ont été retravaillés avec délicatesse. Ils portent toujours les traces de leur naissance oratoire. Ah, l'importance du contexte en archivistique! Nous laissons ici la place à $\mathrm{M}^{\mathrm{me}}$ Baillargeon, notre rédactrice en chef invitée, pour vous présenter ce numéro tout spécial.

Bonne lecture!

\section{Vivianne MARÉCHAL}

Directrice de la revue Archives

Archiviste, Service des archives et de gestion des documents, Université du Québec à Montréal 